\title{
Erratum to: Association between antibodies to carbamylated proteins and subclinical atherosclerosis in rheumatoid arthritis patients
}

Francesca Romana Spinelli ${ }^{1 \dagger}$, Arbi Pecani $^{1 \dagger}$, Francesco Ciciarello ${ }^{2}$, Tania Colasanti ${ }^{1}$, Manuela Di Franco ${ }^{1}$, Francesca Miranda ${ }^{1}$, Fabrizio Conti ${ }^{1}$, Guido Valesini ${ }^{1}$ and Cristiano Alessandri ${ }^{*}$

After the publication of the article [1] it was brought to our attention that an incorrect version of Table 3 was included. The correct version of Table 3 is as shown below.

\section{Author details}

'Department of Internal Medicine and Medical Specialities, Rheumatology, Sapienza University of Rome, Viale de Policlinico 155, 00161 Rome, Italy.

${ }^{2}$ Department of Cardiovascular, Respiratory, Nephrology and Geriatric

Sciences, Sapienza University of Rome, Rome, Italy.

Received: 2 June 2017 Accepted: 5 June 2017

Published online: 16 June 2017

\section{Reference}

1. Spinelli, et al. Association between antibodies to carbamylated proteins and

subclinical atherosclerosis in rheumatoid arthritis patients. BMC

Musculoskelet Disord. 2017;18:214. doi:10.1186/s12891-017-1563-8.

\footnotetext{
* Correspondence: cristiano.alessandri@uniroma1.it

${ }^{\dagger}$ Equal contributors

${ }^{1}$ Department of Internal Medicine and Medical Specialities, Rheumatology,

Sapienza University of Rome, Viale de Policlinico 155, 00161 Rome, Italy

Full list of author information is available at the end of the article
} 
Table 3 Multivariate analysis showing association between autoantibodies and vascular parameters of subclinical atherosclerosis in Rheumatoid Arthritis patients

\begin{tabular}{|c|c|c|c|c|c|c|c|c|c|}
\hline & \multicolumn{3}{|c|}{ Anti-CarP } & \multicolumn{3}{|c|}{ ACPA } & \multicolumn{3}{|l|}{ RF } \\
\hline & $r$ & $\mathrm{P}$ & $\beta$ & $r$ & $\mathrm{P}$ & $\beta$ & $\bar{r}$ & $P$ & $\beta$ \\
\hline Flow Mediated Dilatation (\%, mean \pm SD) & 1.6 & $0.05^{*}$ & 0.400 & 1.5 & 0.1 & 0,222 & 0.2 & 0.7 & 0.421 \\
\hline Cardio Ankle Vascular Index left & 1.7 & $0.04^{*}$ & 0.461 & 1.4 & 0.6 & 0,042 & 0.8 & 0.3 & 0.259 \\
\hline Cardio Ankle Vascular Index right & 2.9 & $0.05^{*}$ & 0,631 & 1.4 & 0.6 & 0,126 & 0.2 & 0.8 & 0.067 \\
\hline Ankle Brachial Index left & 0.3 & 0.2 & 0,175 & 3.5 & $0.01^{*}$ & 0,826 & 0.5 & 0.5 & 0.136 \\
\hline Ankle Brachial Index right & 0.1 & 0.2 & 0,214 & 2.6 & $0.02^{*}$ & 0,619 & 0.7 & 0.5 & 0.157 \\
\hline Carotid Intima Media Thickness left (mm) & 1.5 & $0.03^{*}$ & 0.291 & 2.2 & $0.01^{*}$ & 0.980 & 1.3 & 0.1 & 0.336 \\
\hline Carotid Intima Media Thickness right(mm) & 1.1 & $0.03^{*}$ & 0,294 & 2.1 & $0.01^{*}$ & 0.870 & 1.2 & 0.6 & 0.110 \\
\hline
\end{tabular}

anti-CarP anti-carbamylated protein antibodies, ACPA anti-citrullinated peptides antibodies, RF Rheumatoid Factor *statistically significant at $p<0.05$ 